Journal of Mathematics and Informatics

Vol. 17, 2019, 107-112

ISSN: 2349-0632 (P), 2349-0640 (online)

Published 10 September 2019

www.researchmathsci.org

DOI: http://dx.doi.org/10.22457/jmi.153av17a10

Journal of

Mathematics and

Informatics

\title{
Multiplicative Gourava Indices of Armchair and Zigzag Polyhex Nanotubes
}

\author{
V.R.Kulli \\ Department of Mathematics \\ Gulbarga University, Gulbarga 585106, India \\ e-mail: vrkulli@gmail.com
}

Received 8 August 2019; accepted 8 September 2019

Abstract. In this paper, we compute the multiplicative first and second Gourava indices, multiplicative first and second hyper Gourava indices, multiplicative sum connectivity Gourava index, multiplicative product connectivity Gourava index, general multiplicative first and second Gourava indices of armchair polyhex nanotubes, zigzag polyhex nanotubes.

Keywords: Multiplicative Gourava indices, multiplicative hyper Gourava indices, multiplicative sum connectivity Gourava index, multiplicative product connectivity Gourava index, nanotubes.

AMS Mathematics Subject Classification (2010): 05C05, 05C12, $05 C 35$

\section{Introduction}

Let $G$ be a finite, simple, connected graph with vertex set $V(G)$ and edge set $E(G)$. The degree $d_{G}(v)$ of a vertex $v$ is the number of vertices adjacent to $v$. The edge connecting the vertices $u$ and $v$ will be denoted by $u v$. We refer to [1] for other graph terminology and notation.

A molecular graph is a graph such that the vertices correspond to the atoms and edges to the bonds. A single number that can be used to characterize some property of the graph of molecular is called a topological index or graph index. Chemical Graph Theory is a branch of Mathematical Chemistry whose focus of interest is to finding topological indices of a molecular graph which correlate well with chemical properties of the chemical molecules. Numerous topological indices have been considered in Theoretical Chemistry and have found some applications in QSPR/QSAR study see [2, 3].

In [4], Kulli introduced the first Gourava index of a graph $G$, defined as

$$
G O_{1}(G)=\sum_{u v \in E(G)}\left[d_{G}(u)+d_{G}(v)+d_{G}(u) d_{G}(v)\right]
$$

The second Gourava index [4] of a graph $G$ is defined as

$$
G O_{2}(G)=\sum_{u v \in E(G)}\left(d_{G}(u)+d_{G}(v)\right)\left(d_{G}(u) d_{G}(v)\right)
$$


Recently, some Gourava indices were introduced and studied such as hyper Gourava indices [5], sum connectivity Gourava index [6], product connectivity Gourava index [7], general first and second Gourava indices [8]. defined as

We introduce the multiplicative first and second Gourava indices of a graph,

$$
\begin{aligned}
& G O_{1} I I(G)=\prod_{u v \in E(G)}\left[\left(d_{G}(u)+d_{G}(v)\right)+\left(d_{G}(u) d_{G}(v)\right)\right], \\
& G O_{2}(G)=\prod_{u v E(G)}\left(d_{G}(u)+d_{G}(v)\right)\left(d_{G}(u) d_{G}(v)\right) .
\end{aligned}
$$
graph $G$ as

Also we propose the multiplicative first and second hyper Gourava indices of a

$$
\begin{aligned}
& H G O_{1} I I(G)=\prod_{u \in E(G)}\left[\left(d_{G}(u)+d_{G}(v)\right)+\left(d_{G}(u) d_{G}(v)\right)\right]^{2}, \\
& H G O_{2}(G)=\prod_{u \in E(G)}\left[\left(d_{G}(u)+d_{G}(v)\right)\left(d_{G}(u) d_{G}(v)\right)\right]^{2} .
\end{aligned}
$$

Furthermore, we introduce the multiplicative sum connectivity Gourava index and multiplicative product connectivity Gourava index of a graph $G$, defined as

$$
\begin{aligned}
& \operatorname{SGOII}(G)=\prod_{u \in E(G)} \frac{1}{\sqrt{\left(d_{G}(u)+d_{G}(v)\right)+\left(d_{G}(u) d_{G}(v)\right)}}, \\
& \operatorname{PGOII}(G)=\prod_{u v \in E^{(G)}} \frac{1}{\sqrt{\left(d_{G}(u)+d_{G}(v)\right)\left(d_{G}(u) d_{G}(v)\right)}} .
\end{aligned}
$$

Finally, we define the general multiplicative first and second Gourava indices of a graph $G$ as

$$
\begin{gathered}
G O_{1}^{a} I I(G)=\prod_{u v \in E(G)}\left[\left(d_{G}(u)+d_{G}(v)\right)+\left(d_{G}(u) d_{G}(v)\right)\right]^{a}, \\
G O_{2}^{a}(G)=\prod_{u v E(G)}\left[\left(d_{G}(u)+d_{G}(v)\right)\left(d_{G}(u) d_{G}(v)\right)\right]^{a}
\end{gathered}
$$

where $a$ is a real number.

Recently, some different multiplicative indices were studied, for example, in $[9,10]$.

In this paper, we consider armchair polyhex nanotubes and zigzag polyhex nanotubes. Some degree based topological indices of these nanotubes were studied in [11, 12, 13]. Multiplicative indices and multiplicative connectivity indices have significant importance to collect information about properties of chemical compounds [3].

In this paper, some multiplicative Gourava indices of armchair polyhex and zigzag nanotures are determined.

\section{Results for Armchair Polyhex Nanotubes}

Carbon polyhex nanotubes are the nanotubes whose cylindrical surface nanotubes are the nanotubes whose cylindrical surface is made up of entirely hexagons. These polyhex nanotubes exist in nature with remarkable stability and poses very interesting electrical, mechanical and thermal properties. Armchair polyhex nanotube is denoted by $T U A C_{6}[p$, $q$ ], where $p$ is the number of hexagons in a row and $q$ is the number of hexagons in a column. A graph of $\operatorname{TUAC}_{6}[p, q]$ is shown in Figure 1. 
Multiplicative Gourava Indices of Armchair and Zigzag Polyhex Nanotubes

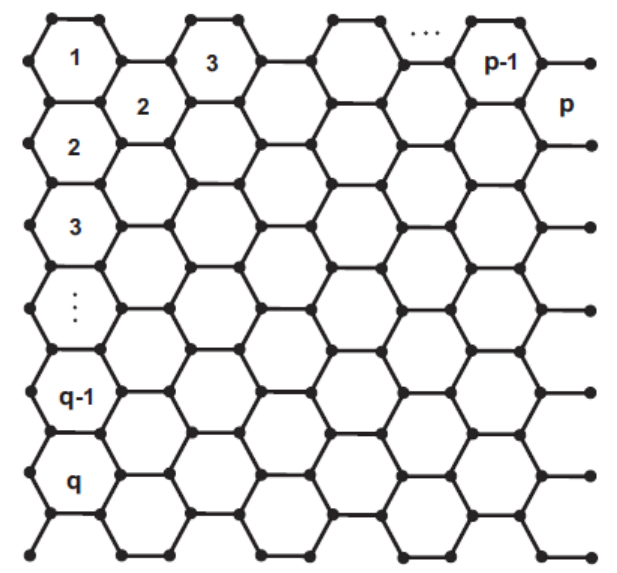

Figure 1: Graph of $T U A C_{6}[p, q]$

Let $G=T U A C_{6}[p, q]$ where $p, q \geq 1$. By calculation, $G$ has $2 p(q+1)$ vertices and $3 p q+2 p$ edges. There are three types of edges based on degree of end vertices of each edge as given Table 1 .

Table 1: Edge partition of $T U A C_{6}[p, q]$

\begin{tabular}{lccc}
\hline$d_{G}(u), d_{G}(v) \backslash u v \in E(G)$ & $(2,2)$ & $(2,3)$ & $(3,3)$ \\
Number of edges & $P$ & $2 p$ & $3 p q-p$ \\
\hline
\end{tabular}

Theorem 1. The general multiplicative first Gourava index of $\operatorname{TUAC}_{6}[p, q]$ is $G O_{1}^{a} I I\left(T U A C_{6}[p, q]\right)=8^{a p} \times 11^{2 a p} \times 15^{a(3 p q-p)}$.

Proof: Let $G=T U A C_{6}[p, q]$. By using equation (1) and Table 1, we deduce

$$
\begin{aligned}
G O_{1}^{a} I I\left(T U A C_{6}\right. & {[p, q])=\prod_{u v E(G)}\left[\left(d_{G}(u)+d_{G}(v)\right)+\left(d_{G}(u) d_{G}(v)\right)\right]^{a} } \\
& =[(2+2)+(2 \times 2)]^{a p} \times[(2+3)+(2 \times 3)]^{2 a p} \times[(3+3)+(3 \times 3)]^{a(3 p q-p)} \\
& =8^{a p} \times 11^{2 a p} \times 15^{a(3 p q-p) .} .
\end{aligned}
$$

We obtain the following results by using Theorem 1 .

Corollary 1.1. The multiplicative first Gourava index of $\operatorname{TUAC}_{6}[p, q]$ is

$$
G O_{1} I I\left(\text { TUAC }_{6}[p, q]\right)=8^{p} \times 11^{2 p} \times 15^{3 p q-p} .
$$

Corollary 1.2. The multiplicative first hyper Gourava index of $\operatorname{TUAC}_{6}[p, q]$ is

$$
H G O_{1} I I\left(\text { TUAC }_{6}[p, q]\right)=8^{2 p} \times 11^{4 p} \times 15^{6 p q-2 p} .
$$

Corollary 1.3. The multiplicative sum connectivity Gourava index of $T U A C_{6}[p, q]$ is

$$
\operatorname{SGOII}\left(\operatorname{TUAC}_{6}[p, q]\right)=\left(\frac{1}{\sqrt{8}}\right)^{2 p} \times\left(\frac{1}{\sqrt{11}}\right)^{2 p} \times\left(\frac{1}{\sqrt{15}}\right)^{3 p q-p} .
$$


Proof: Put $a=1,2,-1 / 2$ in equation (3), we get the desired results respectively.

Theorem 2. The general multiplicative second Gourava index of $\operatorname{TUAC}_{6}[p, q]$ is

$$
G O_{2}^{a} I I\left(T U A C_{6}[p, q]\right)=16^{a p} \times 30^{2 a p} \times 54^{a(3 p q-p)} .
$$

Proof: Let $G=T U A C_{6}[p, q]$. From equation (2) and by using Table 1, we derive

$$
\begin{aligned}
G O_{2}^{a} I I\left(\text { TUAC }_{6}[p, q]\right)=\prod_{u v E E(G)}\left[\left(d_{G}(u)+d_{G}(v)\right)+\left(d_{G}(u) d_{G}(v)\right)\right]^{a} \\
=[(2+2) \times(2 \times 2)]^{a p} \times[(2+3) \times(2 \times 3)]^{2 a p} \times[(2+3) \times(2 \times 3)]^{a(3 p q-p)} \\
=16^{a p} \times 30^{2 a p} \times 54^{a(3 p q-p)} .
\end{aligned}
$$

We establish the following results by using Theorem 2 .

Corollary 2.1. The multiplicative second Gourava index of $T U A C_{6}[p, q]$ is

$$
\mathrm{GO}_{2} I I\left(\text { TUAC }_{6}[p, q]\right)=16^{p} \times 30^{2 p} \times 54^{3 p q-p} .
$$

Corollary 2.2. The multiplicative second hyper Gourava index of $T U A C_{6}[p, q]$ is

$$
\mathrm{HGO}_{2} I I\left(\text { TUAC }_{6}[p, q]\right)=16^{2 p} \times 30^{4 p} \times 54^{6 p q-2 p} .
$$

Corollary 2.3. The multiplicative product connectivity Gourava index of $\operatorname{TUAC}_{6}[p, q]$ is

$$
\operatorname{PGOII}\left(\operatorname{TUAC}_{6}[p, q]\right)=\left(\frac{1}{4}\right)^{p} \times\left(\frac{1}{\sqrt{30}}\right)^{2 p} \times\left(\frac{1}{\sqrt{54}}\right)^{3 p q-p} .
$$

Proof: Put $a=1,2,-1 / 2$ in equation (4), we obtain the desired results respectively.

\section{Results for Zigzag Polyhex Nanotubes}

Zigzag polyhex nanotube is denoted by $\operatorname{TUZC}_{6}[p, q]$, where $p$ is the number of hexagons in a row and $q$ is the number of hexagons in a column. A graph of $T U Z C_{6}[p, q]$ is presented in Figure 2.

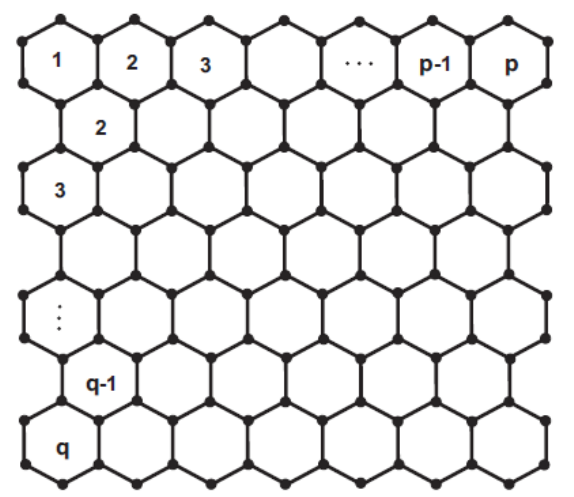

Figure 2: Graph of $\operatorname{TUZC}_{6}[p, q]$

Let $G=T U Z C_{6}[p, q]$, where $p, q \geq 1$. By calculation, $G$ has $2 p(q+1)$ vertices and $3 p q+2 p$ edges. There are two types of edges based on degree of end vertices of each edge as given in Table 2 . 
Multiplicative Gourava Indices of Armchair and Zigzag Polyhex Nanotubes

Table 2: Edge partition of $T U Z C_{6}[p, q]$

\begin{tabular}{lcc}
$d_{G}(u), d_{G}(v) \backslash u v \in E(G)$ & $(2,3)$ & $(3,3)$ \\
Number of edges & $4 p$ & $3 p q-2 p$ \\
\hline
\end{tabular}

Theorem 3. The general multiplicative first Gourava index of $T U Z C_{6}[p, q]$ is given by

$$
G O_{1}^{a} I I\left(T U Z C_{6}[p, q]\right)=11^{4 a p} \times 15^{a(3 p q-2 p)} .
$$

Proof: Let $G=T U Z C_{6}[p, q]$. From equation (1) ad by using Table 2, we obtain

$$
\begin{aligned}
G O_{1}^{a} I I\left(T U Z C_{6}[p, q]\right) & =\prod_{u v \in E(G)}\left[\left(d_{G}(u)+d_{G}(v)\right)+\left(d_{G}(u) d_{G}(v)\right)\right]^{a} \\
& =[(2+3)+(2 \times 3)]^{4 a p} \times[(3+3)+(3 \times 3)]^{a(3 p q-2 p)} \\
& =11^{4 a p} \times 15^{a(3 p q-2 p)} .
\end{aligned}
$$

We establish the following results by using Theorem 3 .

Corollary 3.1. The multiplicative first Gourava index of $T U Z C_{6}[p, q]$ is

$$
G O_{1} I I\left(T U Z C_{6}[p, q]\right)=11^{4 p} \times 15^{3 p q-2 p} .
$$

Corollary 3.2. The multiplicative first hyper Gourava index of $T U Z C_{6}[p, q]$ is

$$
H G O_{1} I I\left(T U Z C_{6}[p, q]\right)=11^{8 p} \times 15^{6 p q-4 p} .
$$

Corollary 3.3. The multiplicative sum connectivity Gourava index of $T U Z C_{6}[p, q]$ is

$$
\operatorname{SGOII}\left(\operatorname{TUZC}_{6}[p, q]\right)=\left(\frac{1}{\sqrt{11}}\right)^{4 p} \times\left(\frac{1}{\sqrt{15}}\right)^{3 p q-2 p} .
$$

Proof: Put $a=1,2,-1 / 2$ in equation (5), we obtain the desired results respectively.

Theorem 4. The general multiplicative second Gourava index of $T U Z C_{6}[p, q]$ is given by

$$
G O_{2}^{a} I I\left(T U Z C_{6}[p, q]\right)=30^{4 a p} \times 54^{a(3 p q-2 p)} .
$$

Proof: Let $G=T U Z C_{6}[p, q]$. By using equation (2) and Table 2, we have

$$
\begin{aligned}
G O_{2}^{a} I I\left(T U Z C_{6}[p, q]\right) & =\prod_{u v \in E(G)}\left[\left(d_{G}(u)+d_{G}(v)\right)\left(d_{G}(u) d_{G}(v)\right)\right]^{a} \\
& =[(2+3) \times(2 \times 3)]^{4 a p} \times[(3+3) \times(3 \times 3)]^{a(3 p q-2 p)} \\
& =30^{4 a p} \times 54^{a(3 p q-2 p)} .
\end{aligned}
$$

Corollary 4.1. The multiplicative second Gourava index of $T U Z C_{6}[p, q]$ is

$$
\mathrm{GO}_{2} I I\left(\operatorname{TUZC}_{6}[p, q]\right)=30^{4 p} \times 54^{3 p q-2 p} .
$$

Corollary 4.2. The multiplicative second hyper Gourava index of $T U Z C_{6}[p, q]$ is 


$$
\begin{gathered}
\text { V.R.Kulli } \\
H G O_{2} I I\left(T U Z C_{6}[p, q]\right)=30^{8 p} \times 54^{6 p q-4 p} .
\end{gathered}
$$

Corollary 4.3. The multiplicative product connectivity Gourava index of $T U Z C_{6}[p, q]$ is

$$
\operatorname{PGOII}\left(\text { TUZC }_{6}[p, q]\right)=\left(\frac{1}{\sqrt{30}}\right)^{4 p} \times\left(\frac{1}{\sqrt{54}}\right)^{3 p q-2 p} .
$$

Proof: Put $a=1,2,-1 / 2$ in equation (6), we get the desired results respectively.

\section{Conclusion}

In this paper, we have studied the multiplicative Gourava indices of chemically interesting armchair polyhex and zigzag polyhex nanotubes. However, there are many other nanostructures which are not covered here. Thus, for further research, the multiplicative Gourava indices of several other nanostructures can be considered.

Acknowledgement. The author is thankful to the referee for useful suggestions.

\section{REFERENCES}

1. V.R.Kulli, College Graph Theory, Vishwa International Publications, Gulbarga, India (2012).

2. I.Gutman and O.E. Polansky, Mathematical Concepts in Organic Chemistry, Springer, Berlin (1986).

3. V.R. Kulli, Multiplicative Connectivity Indices of Nanostructures, LAP LEMBERT Academic Publishing (2018).

4. V.R.Kulli, The Gourava indices and coindices of graphs, Annals of Pure and Applied Mathematics, 14(1) (2017) 33-38.

5. V.R. Kulli, On hyper-Gourava indices and coindices, International Journal of Mathematical Archive, 8(12) (2017) 116-120.

6. V.R.Kulli, On the sum connectivity Gourava index, International Journal of Mathematical Archive, 8(7) (2017) 211-217.

7. V.R.Kulli, The product connectivity Gourava index, Journal of Computer and Mathematical Sciences, 8(6) (2017) 235-242.

8. V.R. Kulli, Computation of some Gourava indices of titania nanotubes, International Journal of Fuzzy Mathematical Archive, 12(2) (2017) 75-81.

9. V.R. Kulli, On multiplicative F-indices and multiplicative connectivity F-indices of chemical networks, International Journal of Current Research in Science and Technology, 5(2) (2019)1-10.

10. V.R. Kulli, Multiplicative connectivity KV indices of dendrimers, Journal of Mathematics and Informatics, 15 (2019) 1-7.

11. S. Hayat, S. Wang and J. B. Liu, Valency based topological descriptors of chemical networks, and their applications, Applied Mathematical Modelling, 60(2018) 164178.

12. V.R. Kulli, Reduced second hyper Zagreb index and its polynomial of certain silicate networks, Journal of Mathematics and Informatics, 14 (2018) 11-16.

13. P.Gayatri and U.Priyanka, Degree based topological indices of zigzag chain, Journal of Mathematics and Informatics, 11(2017) 83-93. 